Letras

n 47

Percursos literánios 
Letras / Universidade Federal de Santa Maria. Centro de Artes e Letras. Programa de Pós-graduação em Letras. - № 1, jan./ jun. (1991) . Santa Maria, 1991 -

Semestral

Vol. 23, nº 47 (jul./dez. 2013)

ISSN 1519-3985

1. Literatura. 2. Literatura - Periódicos. 3. Linguística.

I. Universidade Federal de Santa Maria - UFSM. II. Centro de Artes e Letras - CAL. III. Programa de Pós-graduação em Letras.

Ficha catalográfica elaborada por Fernando Leipnitz CRB-10/1958 Biblioteca Central/UFSM 


\title{
Percursos literários
}

\author{
Maria Eulália Ramicelli (UFSM) \\ Sandra Guardini Teixeira Vasconcelos (USP) \\ (organizadoras)
}

№ 47, JULHO/DEZEMBRO DE 2013

Programa de Pós-Graduação em Letras

Universidade Federal de Santa Maria

Santa Maria - Rio Grande do Sul

ISSN 1519-3985

Letras | Santa Maria |v. $23 \mid$ n. $47 \mid$ p. 1-212 | jul./dez. 2013 
Reitor

Felipe Martins Müller

Diretor do Centro de Artes e Letras Pedro Brum Santos

Coordenadora do Programa de Pós-Graduação em Letras Marcia Cristina Corrêa

\section{Comissão Editorial}

Pedro Brum Santos (Editor-Chefe)

Tania Regina Taschetto

Marília de Araujo Barcellos

Simone de Mello de Oliveira

\section{Conselho Editorial}

Amanda Eloina Scherer (UFSM)

Aracy Ernst Pereira (UCPel)

Beatriz M. Eckert-Hoff (UNIVÁs)

Claudete Moreno Ghiraldelo (ITA)

Cristiane Pereira Dias (Unicamp)

Désirée Motta Roth (UFSM)

Diana Luz Pessoa de Barros (USP)

Euridice Figueiredo (UFF)

Freda Indursky (UFRGS)

Gesualda Rasia (UFPR)

Glaís Sales Cordeiro (Université de Genève)

José Luís Jobim de Salles Fonseca (UERJ)

Lúcia Helena Martins Gouvêa (UFRJ)

Luiz Francisco Dias (UFMG)

Luiz Paulo da Moita Lopes (UFRJ)

Manoel Luiz Gonçalves Corrêa (USP)

Marcia Azevedo de Abreu (Unicamp)

Maria Cleci Venturini (Unicentro)

Maria da Glória C. Di Fanti (PUCRS)

Maria José R. Faria Coracini (Unicamp)

Raquel Salek Fiad (Unicamp)

Regina Ritter Lamprecht (PUCRS)

Regina Zilberman (UFRGS)

Rita Terezinha Schmidt (UFRGS)

Roberto Acízelo de Souza (UERJ)

Sheila Elias de Oliveira (Unicamp)

Valdir Prigol (UFFS)

Preparação e Revisão de Texto

Tagiane Mai (UFSM)

Tania Regina Taschetto (UFSM)

Capa, Projeto Gráfico e Diagramação Daniele Bubans e Evandro Bertol

Periodicidade

Semestral

\section{Editora}

PROGRAMA DE

PÓS-GRADUAÇÃO EM LETRAS

Universidade Federal de Santa Maria

Centro de Educação, Letras e Biologia

Prédio 16, Sala 3222 - Bloco A2.

Campus Universitário - Camobi.

97105-900 - Santa Maria, RS - Brasil

Fone: 5532208359

Fone/fax: 5532208025

E-mail: revistaletras.letras@gmail.com

www.ufsm.br/revistaletras

\section{Política Editorial}

A revista Letras, Periódico Científico, compila artigos resultantes de pesquisa científica original de caráter significativo para as áreas dos Estudos Linguísticos e Literários. Essa publicação tem periodicidade semestral desde 1991 e está vinculada ao Programa de Pós-Graduação em Letras (PPGL) da Universidade Federal de Santa Maria (UFSM). Cada publicação fica sob a responsabilidade de pelo menos um pesquisador vinculado ao PPGL que assume a função de organizador. Os artigos enviados devem atender à chamada temática $\mathrm{e}$ são avaliados, anonimamente, por dois membros do conselho editorial e assessorados, se necessário, por parecerista ad hoc (sobretudo em caso de empate).

A revista Letras publica artigos de pesquisadores brasileiros e estrangeiros, que podem ser escritos em português, francês, espanhol ou inglês. Para artigos escritos em português, Título, Resumo e Palavras-chave devem aparecer em português e inglês. Para artigos escritos em outras línguas, Título, Resumo e Palavras-chave devem ser escritos na língua do artigo e em inglês, exceto aqueles em que o texto está em inglês. Os originais apresentados não devem ter sido publicados ou submetidos simultaneamente a outro periódico. Ficam concedidos à Revista todos os direitos autorais referentes aos trabalhos publicados.

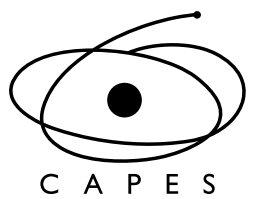

Esta publicação conta com o apoio institucional da Coordenação de Aperfeiçoamento de Pessoal de Nível Superior. 